\title{
Further studies on platelet adhesiveness and serum cholesteryl linoleate levels in multiple sclerosis
}

\author{
H. SANDERS, R. H. S. THOMPSON, H. PAYLING WRIGHT, AND \\ K. J. ZILKHA \\ From the Courtauld Institute of Biochemistry, Middlesex Hospital Medical School, \\ Department of Pharmacology, Royal College of Surgeons, King's College Hospital, and \\ National Hospital, Queen Square, London
}

Earlier work indicated a fall in the level of linoleate, determined by gas chromatography, in the serum of patients in the active phases of multiple sclerosis (Baker, Thompson, and Zilkha, 1964; 1966). In a series of 35 patients with multiple sclerosis the level in the serum of the cholesteryl linoleate fraction, separated by thin-layer chromatography, was reduced in patients with clinical evidence of recent deterioration (Baker, Sanders, Thompson, and Zilkha, 1965).

Increased adhesiveness of platelets in the blood of patients with multiple sclerosis had been described by several groups of workers (Nathanson and Savitsky, 1952; Fog, Kristensen, and Helweg-Larsen, 1955; Caspary, Prineas, Miller, and Field, 1965; Wright, Thompson, and Zilkha, 1965; Millar, Merrett, and Dalby, 1966).

The present paper describes work in which both serum cholesteryl linoleate and platelet adhesiveness measurements have been made on samples of the same blood from a series of patients in order to relate in more detail such changes to the activity and severity of the disease; the relationship between these two measurements in this group of patients is also considered.

\section{METHODS}

Forty healthy controls and 49 patients with multiple sclerosis were investigated.

The control subjects ( 22 men and 18 women) were laboratory staff, students and blood donors, whose ages ranged from 17 to 62 years.

The cases of multiple sclerosis ( 23 men and 26 women) attended the National Hospital, Queen Square, King's College Hospital, or the Middlesex Hospital; their ages ranged from 13 to 58 years. Thirteen attended as outpatients, and 36 as in-patients. They have been divided into two groups, active and inactive, based on a clinical assessment made before the laboratory investigations were started. We have defined 'recent activity' as the appearance of new physical signs accompanied by clinical deterioration without remission during the previous month.

In a series of six out-patients, estimations of cholesteryl linoleate and of platelet adhesiveness were also made at fortnightly intervals for periods of up to seven months in the hope that it might be possible to correlate changes in these values with alterations in the clinical state of the patient.

All blood samples were taken from the antecubital vein between 8.30 and 9 a.m. after an overnight fast.

ESTIMATION OF CHOLESTERYL LINOLEATE Samples used for the estimation of cholesteryl linoleate were allowed to stand at room temperature; the serum was separated within $2 \mathrm{hr}$. The extraction of the serum lipids was carried out as described by Webster (1962). Aliquots of the total lipid extract were applied to $\mathrm{AgNO}_{3}$-impregnated silicic acid plates prepated according to the procedure of Morris (1963). The di-unsaturated cholesteryl esters were separated from other cholesteryl esters and also from free cholesterol by developing in 50/50 (v/v) peroxide-free diisopropyl ether-hexane $\left(67-70^{\circ}\right)$. The plates were lightly sprayed with $0.01 \%$ dichloro-fluorescein in ethanol. The di-unsaturated cholesteryl ester band, identified under ultra-violet light, by comparison with a second plate to which pure cholesteryl linoleate had been applied, was transferred to a funnel plugged with etherwashed cotton wool, and the ester eluted with two $3 \mathrm{ml}$. lots of diethyl ether. After evaporation of the ether, the cholesterol in the eluted ester was estimated by Webster's method (1962) with the single modification that, after addition of the $\mathrm{Fe} \mathrm{Cl}_{3}$ reagent, the tubes were placed in a water-bath at $80^{\circ}$ for 5 min before addition of the $\mathrm{H}_{8} \mathrm{SO}_{4}$ to ensure constancy of colour yield.

PLATELET COUNTS AND ADHESIVENESS MEASUREMENTS Venous blood samples were taken, without frothing, through 19-gauge needles into plastic syringes containing enough $3 \cdot 19 \%$ trisodium citrate solution to give a $9: 1$ mixture. Platelet counts and adhesiveness measurements were made at room temperature between $30 \mathrm{~min}$ and $1 \mathrm{hr}$ of being drawn, when the plateau of adhesiveness had been reached (Hellem, 1960; Fyfe and Hamilton, 1967).

Adhesiveness was measured by a modification (Hirsh 
and McBride, 1965) of Hellem's (1960) method. For this $2 \mathrm{ml}$. of whole blood were driven, with a syringepump, through plastic columns $8 \mathrm{~cm}$ long containing $2.5 \mathrm{~g}$ glass beads (Reflex Perlen, $0.5 \mathrm{~mm}$ diameter); the blood was in contact with the beads for $30 \pm 1 \mathrm{sec}$. Platelet counts were made on blood before and after its passage through the column using a modification (Wright, 1941) of the Rees-Ecker method. The percentage decrease in count was taken as a measure of platelet adhesiveness.

Because platelet adhesiveness rises with the haematocrit value (Hellem, 1960; Hirsh, McBride, and Dacie, 1966), the packed-cell volume was determined for each sample. In the very few instances in which the PCV was reduced, the platelet adhesiveness was measured in a sample enriched with its own erythrocytes to procure a PCV within normal limits.

\section{RESULTS}

CHOLESTERYL LINOLEATE LEVELS Table I shows the mean values of serum cholesteryl linoleate levels in the various groups of patients and normal control subjects. For the six patients on whom repeated estimations were made, only the first results - that is, when they were first examined clinically-have been included in this series. Patients in the inactive stages of the disease show mean levels statistically indistinguishable from the controls where they are under treatment as in-patients or out-patients. The six out-patients in the active stages of the disease, who had recently deteriorated, but whose overall

\section{TABLE I}

MEAN SERUM CHOLESTERYL LINOLEATE LEVELS

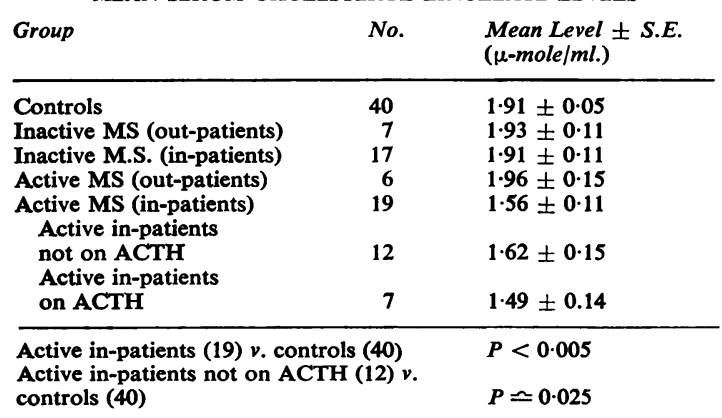

disability was insufficient to necessitate admission to hospital, also show a mean level indistinguishable from the controls. The 19 'active' patients, however, whose degree of disability required their admission to hospital show a mean level that is statistically significantly lower than the controls.

In Table I these 19 'active in-patients' have been subdivided into a group of 12 who had not received ACTH therapy before the withdrawal of the blood sample, and seven who had been receiving ACTH therapy for varying periods of time before the vene $\bar{z}$ section. The mean value for the patients on ACTH is lower than for those who had not received this drugo Since the effect of ACTH on serum cholestery! linoleate levels is not known, as far as we are aware four further patients with multiple sclerosis, admitted to hospital for treatment, had their serum cholesterys linoleate levels measured before and at intervals. after ACTH administration. The results of these estimations are shown in Table II. In two of these: patients (Nos. 29 and 41) there was a considerabless

TABLE II

SERUM CHOLESTERYL LINOLEATE LEVELS IN FOUR PATIENTS WITH MULTIPLE SCLEROSIS BEFORE AND AT INTERVALS AFTER尺 THE START OF ACTH THERAPY

\begin{tabular}{lll} 
Case No. & Before ACTH & After $A C T$ \\
\hline 29 & 2.49 & $1.66(4)$ \\
& & $1.65(6)$ \\
36 & 1.14 & $1.43(11)$ \\
41 & 2.78 & $1.05(8)$ \\
48 & 1.98 & $2.49(2)$ \\
& & $1.47(6)$ \\
& & $1.90(1)$
\end{tabular}

Figures in parentheses $=$ days after start of therapy.

fall in the linoleate level following the start $\frac{\stackrel{\mathrm{T}}{\mathrm{T}} \mathrm{f}}{\mathrm{f}}$ therapy, although in the other two (Nos. 36 and 48) no significant change was noted. Two further patients had estimations carried out on two occasions afger the start of therapy (although no pre-ACTH valtues? were obtained), and these also showed falls frimo 1.62 to $1.28 \mu-\mathrm{mole} / \mathrm{ml}$. (three days) and frompo 2.03 to $1.28 \mu-\mathrm{mole} / \mathrm{ml}$. (nine days), respectivelyo It is, of course, not possible to reach any firm conclusions as to the effect of ACTH from these few observations, and more work is needed to elucidate्यू these findings.

Analysis of the results obtained in the 40 contro subjects according to their age in years appears to show, in agreement with the earlier finding of Lopez-S, Krehl, and Hodges (1967), a positive correlation with age (Fig. 2), but when this is taken into account (Table III) the active in-patients. still tend to have low levels, although the numbers of patients in the three sub-groups are small. From Fig. 3 it will be seen that in the case of the multiple sclerosis patients there is no significant correlation? with age.

B. PLATELET ADHESIVENESS The platelet adhesive 7 ness in bloods from both control and multiple: sclerosis subjects are shown in Table IV, where the groups correspond to those of Table I; the discrepancy in numbers in the corresponding groups is dues to a few patients having had their serum cholesteryt 


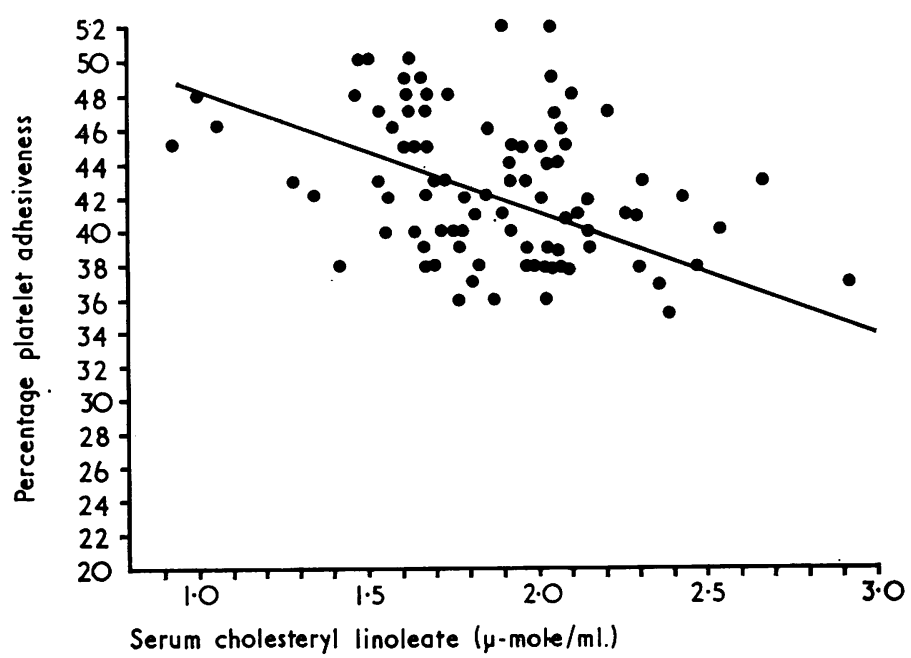

FIG. 1. Correlation of serum cholesteryl linoleate and platelet adhesiveness values in multiple sclerosis patients.

\section{TABLE III}

SERUM CHOLESTERYL LINOLEATE LEVELS IN CONTROL SUBJECTS AND IN IN-PATIENTS WITH ACTIVE MULTIPLE SCLEROSIS ANALYSED ACCORDING TO AGE IN YEARS

\begin{tabular}{llll} 
Age (yr) & $\begin{array}{l}\text { Controls } \\
(\mu-\text {-mole/ml. })\end{array}$ & $\begin{array}{l}\text { All active } \\
\text { in-patients } \\
(\mu-m o l e / m l .)\end{array}$ & $\begin{array}{l}\text { Active in-patients } \\
\text { not on ACTH } \\
(\mu-\text { mole/ml. })\end{array}$ \\
\hline Under 25 & $1.77(16)$ & $1.49(9)$ & $1.45(4)$ \\
$25-40$ & $1.86(12)$ & $1.70(8)$ & $1.79(6)$ \\
Over 40 & $2.18(12)$ & $1.43(2)$ & $1.43(2)$
\end{tabular}

Figures in parentheses $=$ numbers of patients

TABLE IV

MEAN PERCENTAGe PLATELET ADHESIVENESS

\begin{tabular}{lrl} 
Group & No. & Mean Level \pm S.E. \\
\hline Controls & 34 & $30 \pm 0.56$ \\
Inactive MS (out-patients) & 6 & $41 \pm 1.62$ \\
Inactive MS (in-patients) & 16 & $40 \pm 0.69$ \\
$\begin{array}{l}\text { Active MS (out-patients) } \\
\text { Active MS (in-patients) }\end{array}$ & 6 & $44 \pm 1.27$ \\
$\quad \begin{array}{l}\text { Active in-patients } \\
\text { not on ACTH }\end{array}$ & 19 & $47 \pm 0.75$ \\
$\quad \begin{array}{l}\text { Active in-patients } \\
\text { on ACTH }\end{array}$ & 12 & $47 \pm 0.79$ \\
\hline Active in-patients v. normals & 7 & $46 \pm 1.31$ \\
\hline
\end{tabular}

linoleate estimated at times when it was not possible to carry out platelet measurements.

The mean platelet adhesiveness for the groups of inactive multiple sclerosis patients were somewhat above the normal upper limit for the method (range for the method $=26-38 \%$ ), though of the total 22 cases, seven (or one-third) were below the upper limit for normal subjects. The increase in adhesiveness was greater in the clinically active groups of patients, whether seen as in- or outpatients; the means of $44 \%$ (range $42-49 \%$ ) and
$47 \%$ (range $42-52 \%$ ) are significantly raised compared with our control series.

The effect of ACTH therapy on platelet adhesiveness has recently been the subject of a small subsidiary study carried out on blood from patients at the National Hospital, but not restricted to those included in this series; the results confirm our earlier impression (Wright et al., 1965) that ACTH in therapeutic doses does not influence platelet adhesiveness (Langfield and Wright, 1967).

The effects of the patient's age on the adhesiveness of their platelets are shown in Table V. The figures for both the control and multiple sclerosis groups show that age does not influence platelet adhesiveness. The greatest adhesiveness was observed in the

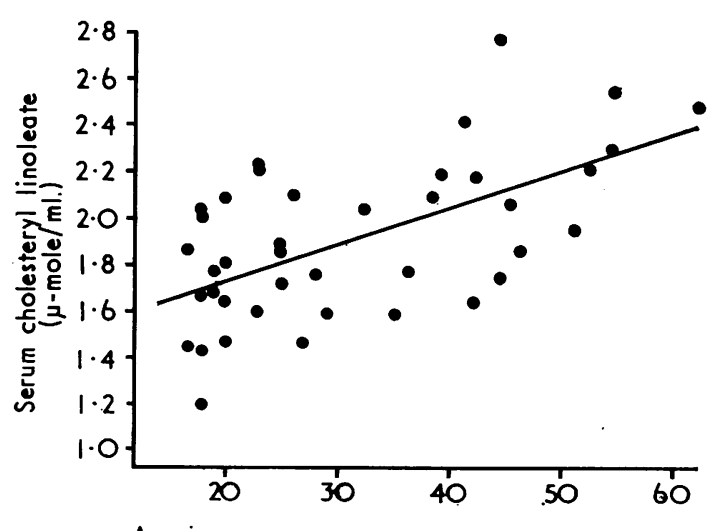

Age in years

FIG. 2. Correlation of serum cholesteryl linoleate levels with age in healthy control subjects. 
TABLE V

PLATELET ADHESIVENESS IN CONTROL SUBJECTS AND IN IN-PATIENTS WITH ACTIVE MULTIPLE SCLEROSIS ANALYSED ACCORDING TO AGE IN YEARS

\begin{tabular}{lll} 
Age $(y r)$ & Controls & $\begin{array}{l}\text { All active } \\
\text { in-patients }\end{array}$ \\
\hline Under 25 & $30 \cdot 8(13)$ & $47 \cdot 8(9)$ \\
$25-40$ & $31 \cdot 8(9)$ & $45 \cdot 9(7)$ \\
Over 40 & $30 \cdot 3(12)$ & $46 \cdot 5(2)$
\end{tabular}

Figures in parentheses $=$ number of patients.

multiple sclerosis group under 25 years in which some of the most acutely and extensively ill patients were included.

\section{DISCUSSION}

The results shown in Table $I$ indicate an inverse relationship between serum cholesteryl linoleate levels and platelet adhesiveness in the multiple sclerosis cases. In the control group, the correlation coefficient was low $(P>0 \cdot 1)$, which suggests that in healthy people the fluctuations of each are independent within the limits of normal. In multiple sclerosis patients, however, a different picture emerges. Figure 1 gives the regression line for all the values for cholesteryl linoleate and platelet adhesiveness from multiple sclerosis patients (including values obtained when the patients were seen on occasions subsequent to their first examination) and shows that a highly significant inverse correlation exists $(P<0.001)$. Though these measurements show this close relationship, the interpretation is obscure; it is probable that each is influenced by changes taking place during the active phase of the disease, rather than the one causing changes in

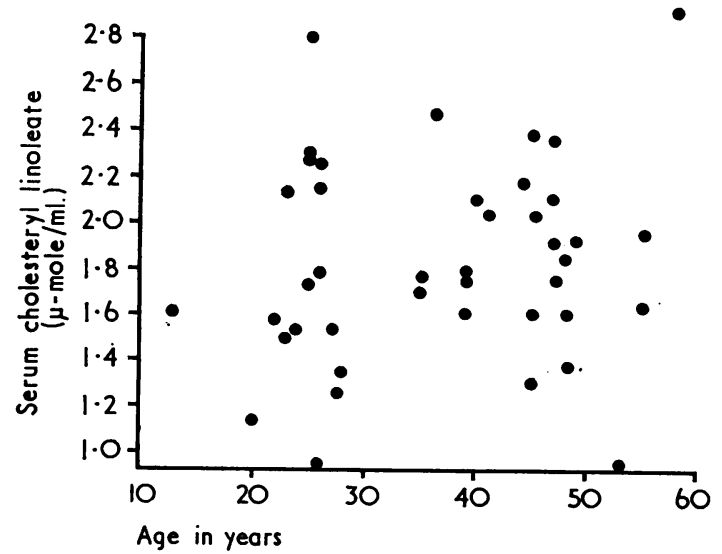

FIG 3. Serum cholesteryl linoleate levels in multiple sclerosis patients plotted against age. the other. Work, now in progress, may throwz light on this problem.

In the series of six cases followed over sevenō months, none of whom had exacerbations sufficiently? severe to warrant admission to hospital during that period, we had the impression that the two measurements fluctuated simultaneously, and that in some instances the changes in cholesteryl linoleate $\frac{\bar{v}}{\mathrm{v}}$. and platelet adhesiveness preceded the phases of clinical deterioration. These changes may possibly: reflect the immediate response to new plaque formation, while clinical deterioration may noto become apparent until demyelination is more음 complete. These serial measurements were, however, $\frac{\bar{s}}{\partial}$ carried out on so few cases, and the observed $\stackrel{\varnothing}{\Phi}$ fluctuations in measurements and in clinical state were in general so slight, that it is not possible to reach definite conclusions from this part of the? work.

Although the number of patients with 'active' $\stackrel{\mathrm{\omega}}{\mathrm{C}}$ multiple sclerosis who were under treatment as out-patients is small, it is of interest that theiro mean cholesteryl linoleate is indistinguishable from $\stackrel{\omega}{\longrightarrow}$ that of the control group, whereas that for 'active' in-patients is significantly lower than the mean fo्s the controls $(P<0.005)$.

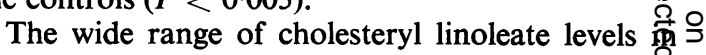
serum samples from healthy individuals (norma range $=1 \cdot 27-2 \cdot 57 \mu$-mole $/ \mathrm{ml}$.) renders the treatment of the results meaningful only when carried out ong statistical basis. The present findings, however. confirm our earlier conclusion that in many patier $\vec{\theta}$ in the severe, active phases of the disease the linoleate $\infty$ level is low. Thus, in the present study $53 \%$ of the 19 'active' in-patients had values lower than $1.6 \mu-\mathrm{mole} / \mathrm{ml}$. and $42 \%$ values lower than 1.4 $\mu$-mole/ml., as compared with $13 \%$ and $2.5 \%$ respectively of the 40 controls (the corresponding figures for the 12 'active' in patients not on ACTH are $50 \%$ and $33 \%$ respectively). Furthermore, although the percentage platelet adhesiveness of the 'active' out-patients is raised, it is higher still in the 'active' in-patients. These observations supportthe conclusion of Millac (1967a) that the increase in adhesiveness is correlated with the extent of the ? disease, as evidenced by clinical disability, and the same would appear to hold for the decrease in the cholesteryl linoleate level. Tables I and IV show that the change in platelet adhesiveness is a more

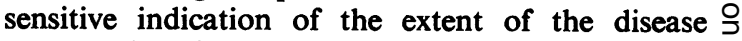
process than is that of cholesteryl linoleate level; $D$ the deviation from normal of adhesiveness measurements is greater than that of cholesteryl linoleate, $N$ and even patients in the 'inactive' phases of the disease show increased adhesiveness although the mean linoleate levels of this group are unchanged. 
Alterations in platelet adhesiveness may depend upon factors which may not necessarily influence cholesteryl linoleate levels. Release of adenosine diphosphate (ADP), from red blood cells is known to cause platelet aggregation (Hellem, 1960; Gaarder, Jonsen, Laland, Hellem, and Owren, 1961); erythrocyte osmotic fragility has been reported to be increased in multiple sclerosis (Laszlo, 1964; Caspary, Sewell, and Field, 1967), and this might allow the liberation of sufficient ADP to alter platelet-to-glass adhesiveness. No correlation between adhesiveness and red cell fragility has however, been demonstrated (Millac, 1968). Millac (1967b), on the other hand, has suggested that the platelet changes may be due to the entry into the blood stream of some substance produced by the acute breakdown of neural tissue, as he has found increased adhesiveness also in patients with invasive intracerebral tumours, but we have as yet no evidence as to the nature of such a substance, if indeed a causative mechanism of this type is concerned with these platelet changes.

\section{SUMMARY}

Serum cholesteryl linoleate and platelet adhesiveness were measured on blood samples from 49 patients with multiple sclerosis and from 40 healthy control subjects.

Cholesteryl linoleate levels were lowered in the group of 'active' patients whose disability was sufficient to warrant admission to hospital. Platelet adhesiveness was increased in the 'inactive' patients, still further increased in the 'active' out-patients, and was higher still in the 'active' patients admitted to hospital.

In the multiple sclerosis cases there was a highly significant inverse correlation $(P<0 \cdot 001)$ between serum cholesteryl linoleate levels and platelet adhesiveness. In the healthy group there was no such correlation.

It is concluded that the changes in these two parameters are probably each the outcome of some other process taking place in the disease, rather than the one causing changes in the other.

We wish gratefully to acknowledge the statistical help and advice provided by Dr. M. J. S. Langman, M.R.C. Statistical Research Unit. Our thanks are also due to our clinical colleagues who allowed us access to cases under their care, and to the Medical Research Council and the Multiple Sclerosis Society for grants in support of this work.

\section{REFERENCES}

Baker, R. W. R., Sanders, H., Thompson, R. H. S., and Zilkha, K. J (1965). Serum cholesterol linoleate levels in multiple sclerosis. J. Neurol. Neurosurg. Psychiat., 28, 212-217.

—, Thompson, R. H. S., and Zilkha, K. J. (1964). Serum fatty acids in multiple sclerosis. J. Neurol. Neurosurg. Psychiat., 27, 408-414.

$-1-1966)$. Changes in the amounts of linoleic acid in the serum of patients with multiple sclerosis. J. Neurol. Neurosurg. Psychiat., 29, 95-98.

Caspary, E. A., Prineas, J., Miller, H., and Field, E. J. (1965). Platelet stickiness in multiple sclerosis. Lancet, 2, 1108-1109.

- Sewell, F., and Field, E. J. (1967). Red blood cell fragility in multiple sclerosis. Brit. med. J., 2, 610-611.

Fog, T., Kristensen, I., and Helweg-Larsen, H. F. (1955). Blood platelets in disseminated sclerosis. Arch. Neurol. (Chic.), 73, 267-285.

Fyfe, T., and Hamilton, E. (1967). Effect of variation of the interval between venepuncture and measurement of platelet adhesiveness by the Payling Wright method. Lancet, 2, 542-543.

Gaarder, A., Jonsen, J., Laland, S., Hellem, A. J., and Owren, P. A. (1961). Adenosine diphosphate in red cells as a factor in the adhesiveness of human blood platelets. Nature (Lond.), 192, 531-532.

Hellem, A. J. (1960). The adhesiveness of human blood platelets in vitro. Scand. J. clin. Lab. Invest., 12, Suppl. No. 57, 1-117.

Hirsh, J., and McBride, J. A. (1965). Increased platelet adhesiveness in recurrent venous thrombosis and pulmonary embolism. Brit. med. J., 2, 797-799.

- - , and Dacie, J. V. (1966). Thrombo-embolism and increased platelet adhesiveness in post-splenectomy thrombocytosis. Aust. Ann. Med., 15, 122.

Langfield, J. A., and Wright, H. P. (1967). Corticotrophin and platelet stickiness. Lancet, 2, 1254.

Laszlo, S. (1964). Fragilité osmotique des globules rouges dans la sclérose en plaques. Acta neurol. belg., 64, 529.

Lopez-S, A., Krehl, W. A., and Hodges, R. E. (1967). Relationship between total cholesterol and cholesteryl esters with age in human blood plasma. Amer. J. clin. Nutr., 20, 808-815

Millac, P. (1967a). Platelet stickiness in multiple sclerosis. Dtsch. $Z$. Nervernheilk, 191, 74-79.

- (1967b). Platelet stickiness in patients with intracranial tumours. Brit. med. J., 4, 25-26.

(1968). Platelet behaviour in multiple sclerosis. Lancet, 1, 246-247.

Millar, J. H. D., Merrett, J. D., and Dalby, A. M. (1966). Platelet stickiness in multiple sclerosis. J. Neurol. Neurosurg. Psychiat., 29, $187-189$.

Morris, L. J. (1963). Fractionation of cholesterol esters by thin-layer chromatography. J. Lipid Res., 4, 357-359.

Nathanson, M., and Savitsky, J. P. (1952). Platelet adhesive index studies in multiple sclerosis and other neurologic disorders. Bull. N.Y. Acad. Med., 28, 462-468.

Webster, D. (1962). The determination of total and ester cholesterol in whole blood, serum or plasma. Clin. Chim. Acta, 7, 277-284.

Wright, H. P. (1941). The adhesiveness of blood platelets in normal subjects with varying concentrations of anti-coagulants. J. Path. Bact., 53, 255-262.

, Thompson, R. H. S., and Zilkha, K. J. (1965). Platelet adhesiveness in multiple sclerosis. Lancet, 2, 1109-1110. 